\title{
Cataract surgery under topical anaesthesia - white or yellow light
}

\author{
Keith Ong ${ }^{1}$, Andrew Yue ${ }^{1}$, Sophie Beka ${ }^{1}$ \\ 'University of Sydney, Sydney, Australia
}

Most surgical microscopes provide a yellow filter to filter out the blue light. Ultraviolet light is already filtered out whether the white or yellow light setting is chosen. Yellow light is used to prevent retinal phototoxicity. ${ }^{1,2}$

The yellow filter of the surgical microscope is usually turned on to provide yellow light after the intraocular lens has been inserted because the microscope light is then focused onto the macula, and a compromised illumination and view is not so critical then. To minimise the risk of phototoxicity, yellow light can be used for the whole cataract operation.

With cataract surgery under topical anaesthesia, the patient can be troubled by the bright microscope light. When retrobulbar or peribulbar local anaesthesia is used, the bright light may not be a significant issue for the patient as the optic nerve is blocked or semi-blocked in the process.

If the patient is not comfortable with the bright microscope light, they tend to move their eyes instead of keeping the eyeball in primary position fixating at the microscope light. A small study was carried out to evaluate patients' comfort and preference for yellow or white light.

The cohort consisted of 29 patients having cataract surgery under topical anaesthesia (Benoxinate $0.4 \%$ and Lignocaine 1\%) and intracameral Lignocaine $1 \% 0.1$ $\mathrm{ml}$. The patients had the cataract surgery by Dr Keith Ong in the month of February 2016. The Zeiss OPMI CS Retroskop (Carl Zeiss; Germany) ophthalmic surgery microscope was used.

Before the start of surgery, the patient was asked to fixate at the bright microscope light. The patient was presented with the white light and yellow light alternately with microscope light brightness at the same setting, and then asked which was more comfortable and preferred.

Most of the patients preferred the yellow light, citing that it was more comfortable.

Twenty-six patients (86.7\%) felt more comfortable with the yellow light and just one patient (3.4\%) said that the white light was more comfortable. Two patients (6.8\%) felt there was no difference in comfort between yellow or white light.

Twenty-three patients $(79.3 \%)$ preferred the yellow light if given a choice and none preferred the white light. Six patients $(20.7 \%)$ had no preference and would accept what the surgeon preferred.

There is variability in the amount of discomfort or photophobia as some patients needed to have their eyelids held apart to keep their eyes open when the microscope light was shone into their eyes for the test. During presentation of white

Correspondence: Dr. Keith Ong. E-mail: keithong@optusnet.com.au 
light, there was stronger blepharospasm.

It was also noted, that after several seconds of looking at the bright light, the patient becomes less troubled by the bright light due to light adaptation and depletion of retinal rhodopsin photopigment. ${ }^{3}$

Light damage to the retina is mainly photochemical rather than thermal. The photochemical hazard can be diminished by reducing the short-wavelengths blue light. ${ }^{5}$ The Zeiss OPMI CS Retroskop operating microscope uses a fibre-optic system to transmit light from a halogen lamp. The UVR filter absorbs radiation with wavelength below $380 \mathrm{~nm}$, and the yellow filter absorbs light radiation below 450 nm. ${ }^{2}$

Different operating microscopes may have different types of filters to block blue light. The addition of filters to exclude light below about $515 \mathrm{~nm}$ has been recommended to eliminate blue light, especially in cases requiring prolonged light exposure. However, a $515 \mathrm{~nm}$ short wavelength cut-off filter will result in a very yellow light. Cut-off filters at wavelengths shorter than $515 \mathrm{~nm}$ to about the range of 420-435 mm will affect colour rendition less, and may still provide a useful reduction in photochemical injury risk. ${ }^{5}$

This small study showed that the majority of patients found the yellow light more comfortable and less glaring, and preferred the yellow light to white light for cataract surgery under topical anaesthesia. Yellow light would also cause less retinal phototoxicity. Hence, if the surgeon is happy with the colour rendition and possible slight compromise of illumination and contrast when using the yellow filter, then it would be preferable to use the microscope's yellow light instead of the white light for the whole operation.

\section{References}

1. Irvine AR, Wood I, Morris BW. Retinal damage from the illumination of the operating microscope. An experimental study in pseudophakic monkeys. Arch Ophthalmol 1984; 102: 1358-65.

2. Michael R, Wegener A. Estimation of safe exposure time from an ophthalmic operating microscope with regard to ultraviolet radiation and blue-light hazards to the eye. J Opt Soc Am A Opt Image Sci Vis 2004; 21 (8): 1388-92.

3. Hall, JE.Guyton and Hall textbook of medical physiology 2016. Thirteenth edition. London, United Kingdom. Elsevier. Chapter 51, p. 653.

4. Stiller H, Rassow B. Possible damage to the eye caused by light from ophthalmologic equipment (Article in German). Klin Monatsbl Augenheilkd 1991; 199(7): 62-6.

5. Food and Drug Administration.1995. FDA Public Health Advisory: Retinal photic injuries from operating microscopes during cataract surgery. [Online] Available at: http://www.fda.gov/ MedicalDevices/Safety/AlertsandNotices/PublicHealthNotifications/ucm062683.html 